- Nota -

\title{
DESENVOLVIMENTO SUSTENTÁVEL E DIREITO HUMANO AO MEIO AMBIENTE: BREVES APONTAMENTOS
}

\author{
Bettina Augusta Amorim Bulzico \\ Professora da Graduação \\ Universidade Positivo \\ bettina.bulzico@gmail.com \\ EDUARDO BIACCHI GOMES \\ Professor de Direito Internacional (Graduação e Mestrado) \\ Faculdades Integradas do Brasil \\ eduardobiacchigomes@gmail.com
}

Recebido: 27 de fevereiro de 2010 / Aceito: 7 de maio de 2010

RESUMO: O desenvolvimento sustentável é tema importante na sociedade internacional globalizada. Deve ocorrer a partir da conscientização, por parte dos povos e dos Estados, no sentido de que a existência de um meio ambiente equilibrado é um direito fundamental de todos e que se trata da efetividade dos direitos do cidadão. Em uma sociedade democrática, o Estado deve, mesmo que de forma soberana, explorar o meio ambiente racionalmente, evitando a degradação. O presente artigo pretende fazer uma reflexão sobre este tema, utilizando-se da teoria e de casos concretos.

RESUM: El desenvolupament sostenible és una matèria important en la societat internacional globalitzada. Ha d'impulsar-se a partir de la conscienciació, per part dels pobles i dels estats, en el sentit de què l'existència d'un medi ambient ecològicament equilibrat és un dret fonamental de tothom i que, en definitiva, es tracta de l'efectivitat dels drets dels ciutadans. En una societat democràtica, l'Estat ha d'utilizar els recursos naturals de manera racional, sense degradar-los. Aquesta nota pretén reflexionar sobre aquesta qüestió, tot utilitzant un punt de vista teòric i casos pràctics. 
RESUMEN: El desarrollo sostenible es una materia importante en la sociedad internacional globalizada. Debe impulsarse a partir de la concienciación, por parte de los pueblos y los estados, en el sentido de que la existencia de un medio ambiente ecológicamente equilibrado es un derecho fundamental de todos y que, en definitva, se trata de la efectividad de los derechos de los ciudadanos. En una sociedad democrática, el Estado debe utilizar los recursos naturales de manera racional, sin degradarlos. Esta nota pretende reflexionar sobre este tema, utilizando un punto de vista teórico y casos prácticos.

ABSTRACT: Sustainable development is an important issue in the globalized international society. It must occur from the awareness by peoples and states, provided that the existence of a balanced environment is a fundamental right of everyone. In short, it is about the real efectiveness of the citizens's rights. In a democratic society, the State must explore their natural resources in a rational way, avoiding degradation. This note aims to set out a reflection on this theme, using a theoretical approach and practical cases as well.

PALAVRAS-CHAVE: Democracia - desenvolvimento sustentável - proteção do Meio Ambiente

PARAULES CLAU: Democràcia — desenvolupament sostenible — protecció del medi ambient

PALABRAS CLAVE: Democracia - Desarrollo sostenible — Protección del medio ambiente

KEYWORDS: Democracy - Sustainable development - Environmental protection 
Sumario: I. Introdução. II. Conceito de Desenvolvimento Sustentável. 1. Breve Histórico. 2. Aplicabilidade do Desenvolvimento Sustentável. III. O Caso Gabcikovo - Nagymaros (Hungria vs. Eslováquia) na CIJ. IV. O Caso das 'Papeleras' no MERCOSUL e a Proteção aos Direitos Humanos; V. Considerações Finais.

\section{INTRODUÇÃO}

A proteção ao meio ambiente é tema que, ao longo das últimas décadas, ganhou destaque preponderante, em todos os meios de comunicação, sejam nacionais ou internacionais. Para além disso, trata-se de um foco prioritário de ações por parte de toda a comunidade internacional no sentido de adotar posturas voltadas à preservação do meio ambiente, como forma de assegurar a vida para as futuras gerações.

A preocupação, antes de tudo, deve-se ao fato de que existe uma séria ameaça de que em um futuro, não muito distante, os recursos ambientais possam ficar cada vez mais escassos, o que seguramente prejudicará a vida do ser humano em nosso planeta.

O termo "proteção ao meio ambiente" não deve significar uma inércia social, ou seja, não pode representar a não utilização e a não exploração dos recursos naturais. É fato que, para movimentar a economia globalizada em que se inserem todas as nações, a utilização dos recursos naturais se faz indispensável. Todavia, de forma consciente e equilibrada, preservando e recuperando referidos recursos, bem como criando fontes alternativas de energia, de forma a não promover o esgotamento e a escassez no ambiente. Trata-se de medida mais do que politicamente correta: é essencial.

O presente artigo tem por finalidade abordar o conceito de proteção ao meio ambiente e Desenvolvimento Sustentável, a partir da vertente dos direitos humanos, notadamente porque a finalidade dessa proteção, em última análise, é salvaguardar a vida humana.

Para tanto, propõe-se a apresentar algumas considerações sobre o histórico e o atual conceito de Desenvolvimento Sustentável e, em seguida, apresentar a aplicabilidade desse termo em casos julgados pelas Cortes Internacionais. Mais especificamente, serão analisados os seguintes casos: a) Gabcikovo - Nagymaros (Hungria vs. Eslováquia), Corte Internacional de Justiça 1997 e b) O chamado caso das papeleras (MERCOSUL, Protocolo de Olivos, 2006). 
Ao final, pretende-se realizar uma reflexão sobre a inter-relação existente entre democracia, o direito humano ao meio ambiente e a aplicabilidade do Desenvolvimento Sustentável.

\section{CONCEITO DE DESENVOLVIMENTO SUSTENTÁVEL}

\section{Breve Histórico}

Ao relacionar desenvolvimento e proteção ambiental, é possível afirmar que o termo Desenvolvimento Sustentável, embora sujeito a disputas e definições de ocasião, aponta para dois sentidos principais. Para os países desenvolvidos, sustentabilidade exige transformações no estilo de vida, melhoria da eficiência energética, moderação do consumo, a preferência pelo uso de recursos naturais renováveis e a reciclagem ou o reaproveitamento dos materiais. Para os países em desenvolvimento, onde existam recursos naturais, trata-se de programar a exploração não predatória que minimize impactos adversos, priorizando a produção de recursos renováveis, reduzindo desigualdades, gerando empregos e renda.

Suas origens são antigas. No final do século XVIII, autores, como THOMAS MALTHUS $^{1}$, já se preocupavam com a relação entre crescimento populacional e capacidade de produção de alimentos. A criação de reservas florestais, por outro lado, era realizada por diferentes povos da Antiguidade, por razões religiosas ou para garantir a prática da caça, passando a ser bastante comum na Idade Média. A partir do desenvolvimento dessas ideias iniciais de criação de espaços protegidos e de preocupação com recursos naturais, surgem, nos Estados Unidos, no final do século XIX, duas correntes de pensamento dentro do movimento ambiental emergente, mais tarde denominadas de preservacionista e conservacionista.

Para os primeiros, como JOHN MUIR ${ }^{2}$, a natureza deveria ser preservada em seu estado primitivo, como objeto de contemplação do homem, necessária à sua expansão

\footnotetext{
${ }^{1}$ A Teoria Populacional Malthusiana foi um sistema ideológico desenvolvido por Thomas MALTHUS, economista, estatístico, demógrafo e estudioso das Ciências Socias. Preocupado com o crescimento populacional acelerado, Malthus, em 1798 publica uma série de idéias alertando a importância do controle da natalidade, afirmando que o bem estar populacional estaria intimamente relacionado com crescimento demográfico do planeta. Malthus acreditava que o crescimento desordenado acarretaria na falta de recursos alimentícios para a população gerando como conseqüência a fome.

${ }^{2}$ John MUIR foi um naturalista e escritor norteamericano do século XIX, que lutou pela preservação do patrimônio natural dos Estados Unidos. Em 1890 convenceu o Congresso dos Estados Unidos a criar o Parque Nacional de Yosemite. A partir daí, ele incentiva a criação de novas reservas como Sequoia,
} 
espiritual. Com base nesse pensamento foi que os Estados Unidos passaram a estabelecer, a partir de 1872 , os parques nacionais, iniciando com Yellowstone no Estado do Wyoming. Vastas áreas ainda bem conservadas eram cercadas, as populações ali residentes expulsas e os espaços abertos apenas à visitação.

Os segundos, como Gifford PINCHOT ${ }^{3}$, entendiam que a providência a ser tomada residisse na utilização racional dos recursos naturais, com base nas experiências de manejo florestal trazidas da Alemanha. Já se pregava, então, a necessidade de garantir às futuras gerações a existência dos recursos naturais, prevenindo-se o desperdício.

Entretanto, o termo "Desenvolvimento Sustentável” propriamente dito, consubstanciado como aquele que corresponde às necessidades do presente sem comprometer as possibilidades das gerações futuras de satisfazer suas próprias necessidades, só foi consagrado no texto do Relatório Brundtland (1987). A partir de então passou a ser uma meta vislumbrada por toda a comunidade internacional para a proteção do meio ambiente como Direito Humano.

Posteriormente, a Declaração do Rio (1992) fez referência ao Desenvolvimento Sustentável em cinco de seus Princípios ${ }^{4}$. A partir deles, visa-se a implementar o desenvolvimento de modo a permitir que sejam atendidas as necessidades das gerações presentes sem comprometer as das gerações futuras. Assim sendo, a orientação emanada é no sentido de que a proteção ambiental deva fazer parte do processo de desenvolvimento e, portanto, não pode ser considerada isolada deste.

Acontecimentos posteriores, como a Rio+5 (1997), a Conferência de Habitat II, em Istambul (2000), e a Conferência de Johanesburgo (2002) vieram a reforçar a necessidade de se implantar projetos, em nível local e global, que contemplem o Desenvolvimento Sustentável. É possível e extremamente necessário que continue havendo o desenvolvimento e o progresso da humanidade, desde que ocorra de forma equilibrada, mediante a gestão racional dos recursos naturais disponíveis e a utilização das modernas técnicas de gerenciamento.

Monte Rainier, Parque Nacional Floresta Petrificada e o Parque Nacional Grand Canyon, passando a ser chamado de "o pai dos sistemas de parques nacionais". Em 1892, Muir e seus discípulos criam o Sierra Clube, com a função inicial de proteger a reserva de Yosemite. Em 1901, JOHN MUIr publicou Nos Parcs Nationaux.

${ }^{3}$ Gifford PINCHOT, defendia a conservação dos recursos naturais através do seu uso racional, (esta corrente se baseava em três princípios: o uso dos recursos naturais pela geração presente; a prevenção do desperdício; e o desenvolvimento dos recursos naturais para muitos e não para poucos).

${ }^{4}$ Princípios no 3 ; 4; 8; 20; e 21 da Declaração do Rio-92. 


\section{Aplicabilidade do Desenvolvimento Sustentável}

Seu objetivo principal é manter o ponto de equilíbrio entre preservação e progresso econômico, sem prejudicar o acesso das futuras gerações aos recursos naturais. Para atingir tal fim, desconsideram-se posturas extremas tais como a ideia de defender o crescimento desordenado e predatório ou a postura verde $x$ iita $^{5}$. Abrange ainda questões pertinentes à coibição de agressões ao meio ambiente e à erradicação da pobreza no mundo ${ }^{6}$. Não obstante a incorporação de seu conceito nas Constituições ${ }^{7}$ de grande parte dos Estados, é importante ressaltar que isso pouco significa se não vier acompanhado da incorporação de medidas garantidoras ${ }^{8}$ de sua aplicação.

Quando se alcança consenso em questões extremamente controvertidas como esta, deve-se ter especial cuidado com os conceitos envolvidos. Obviamente não é possível afirmar que o Desenvolvimento Sustentável defendido por ONGs ambientalistas radicais e por indústrias altamente poluidoras tenha o mesmo sentido.

$\mathrm{Na}$ verdade, o discurso da sustentabilidade acabou sendo utilizado e difundido, de forma muitas vezes perversa, como uma cortina de fumaça que visa a encobrir sérias e irreversíveis degradações perpetradas por diferentes grupos econômicos, que nenhuma atenção real dispensam ao ambiente natural. Todavia, não se pode simplesmente abandonar a busca pela sustentabilidade, sob a ótica simplista de ser incompatível com o sistema capitalista, pois, desse modo, estar-se-ia abdicando da única ferramenta que

\footnotetext{
${ }^{5}$ GUERRA, S. C. S., Direito Internacional Ambiental, Maria Augusta Delgado, Rio de Janeiro, 2006, p. 77.

${ }^{6}$ MILARÉ, E., Direito do Ambiente: doutrina, prática, jurisprudência, glossário, Ed. Revista dos Tribunais, São Paulo, 2001, p.150.

${ }^{7}$ No Brasil, o legislador constituinte demonstrou sua preocupação com o tema ao inserir no texto da Constituição Federal de 1988, que o desenvolvimento das atividades econômicas, embora não admitam intervenção do Poder Público, deverão respeitar a algumas diretrizes, entre elas a que impõe a preservação do meio ambiente. Nesse sentido, seus artigos 170 e 225 concebem o princípio do desenvolvimento sustentado: "Artigo 170 - A ordem econômica, fundada na valorização do trabalho humano e na livre iniciativa, tem por fim assegurar a todos existência digna, conforme os ditames da justiça social, observados os seguintes princípios: (...) VI - defesa do meio ambiente." e "Artigo 225 Todos têm direito ao meio ambiente ecologicamente equilibrado, bem de uso comum do povo e essencial à sadia qualidade de vida, impondo-se ao Poder Público e à coletividade o dever de defende-lo e preserválo para as presentes e futuras gerações". Constata-se pelo texto constitucional transcrito a clara presença da idéia de desenvolvimento, com consciência de preservação. A questão da sustentabilidade, assim, coloca-se sobre o tripé da economia, sociedade e meio ambiente, que devem estar equilibrados. Cabe ao Poder Público propiciar o equilíbrio entre esses fatores, buscando meios de compatibilizar o desenvolvimento econômico, com a proteção do ambiente.
}

\footnotetext{
${ }^{8}$ No ordenamento jurídico brasileiro, tem-se a lei $6.938 / 81$, de 02 de setembro que instituiu a Política Nacional do Meio Ambiente, e que em seu art $2^{\circ}$ determina a preservação e a recuperação da qualidade ambienta propícia à vida, visando assegurar condições ao desenvolvimento socioeconômico e a proteção da dignidade da vida humana.
} 
resta para se tentar manter os processos ecológicos e, assim, os recursos bióticos essenciais à sobrevivência da espécie humana em níveis, ao menos, satisfatórios.

Por outro lado, não se deve esquecer que, dentro da discussão da construção de um Desenvolvimento Sustentável, a relação do homem com a natureza é cultural. Como discutido, cada cultura específica constrói, no tempo e no espaço, formas determinadas de relacionamento com o ambiente natural, sustentáveis ou não. Haverá sustentabilidade nessa relação quando não ocorrer o esgotamento das bases materiais de reprodução das atividades econômicas, sociais e culturais.

Falar em Desenvolvimento Sustentável significa falar em prática de ações que se reproduzam no tempo, não podendo, assim, esgotar as bases materiais sobre as quais ocorrem. Não significa, portanto, apenas a manutenção de estoques de recursos naturais para as gerações vindouras, mas a criação de um modo de vida sustentável, que possa ser legado às gerações futuras, em que não haja exclusão social e em que exista um patamar mínimo de igualdade, gerando ações e projetos voltados para a educação, saúde, emprego, habitação, etc ${ }^{9}$.

Como forma de delimitar o tema, foi efetivada uma pesquisa pontual, nos julgados de Cortes Internacionais, acerca do tratamento despendido ao meio ambiente, sua proteção e a busca do equilíbrio com o direito ao desenvolvimento. Inicialmente, apresenta-se um caso emblemático ocorrido na Europa, em 1997, e, em seguida, o foco é direcionado à América Latina, analisando situação datada de 2006.

\section{O CASO GABCIKOVO - NAGYMAROS (HUNGRIA VS. ESLOVÁQUIA) NA CIJ}

Este caso foi especialmente relevante para estudar as possíveis causas do rompimento dos tratados e das circunstancias que excluem a ilicitude de referido ato. A CIJ foi relutante em considerar as alegações da Hungria baseadas num "estado de necessidade" por motivos ambientais.

O conflito encontra sua origem no tratado celebrado em 16 de setembro de 1977, entre a Hungria e a então Thcekoslováquia (denominação dada pelo tratado), sendo que o sistema de barragem "tem por fim valorizar, de modo geral, os recursos naturais da

\footnotetext{
${ }^{9}$ DERANI, C., Direito Ambiental Econômico, Max Limonad, São Paulo, 1997, p. 170.
} 
seção Bratislava - Budapeste do Rio Danúbio, com o fim de desenvolver os setores de

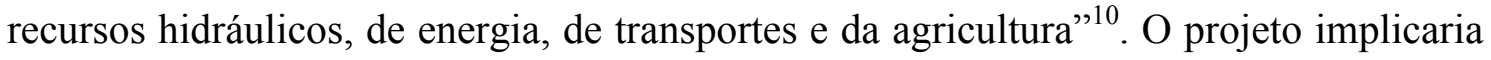
um investimento conjunto objetivando a produção de hidroeletricidade, a melhoria da navegação do trecho referido do Rio Danúbio e a proteção das regiões ribeirinhas contra as inundações.

O Rio Danúbio, com seus 2.850 quilômetros, é o segundo maior da Europa (o primeiro é o Rio Volga). O rio tem sua fonte na Floresta Negra, na Alemanha, a partir de dois pequenos ribeirões chamados Brigach e Breg, que se juntam em Donaueschingen e são chamados Danúbio dali em diante; seu percurso se encerra na Romênia, onde deságua no Mar Negro. O setor referente ao caso deste julgamento abrange aproximadamente 200 quilômetros entre Batislava, na Eslováquia, e Budapeste, na Hungria. Abaixo ou a jusante de Batislava, a declividade do rio diminui sensivelmente criando uma planície aluvial de cascalho e sedimentos arenosos. A fronteira entre os dois Estados é constituída, na maior parte dessa região pelo canal principal do rio. Entre as obras a serem construídas constavam duas centrais hidrelétricas - uma em Gabcíkovo (Eslováquia), com 720MW e outra em Nagymaros (Hungria) com $158 \mathrm{MW}^{11}$.

Todavia, no país húngaro suscitaram críticas ao projeto devido aos possíveis efeitos que este teria em relação ao meio ambiente. Assim, o Governo húngaro decidiu em 13 de maio de 1989, suspender os trabalhos de Nagymaros (momento em que, encontravam-se pendentes vários estudos que deveriam encerrar-se em 31 de julho do mesmo ano). Em 21 de julho o Governo húngaro estendeu a suspensão dos trabalhos em Nagymaros até 31 de outubro. Finalmente em 27 de outubro, decidiu abandonar completamente as atividades.

Durante todo esse tempo as partes mantiveram negociações. A Checoslováquia propôs uma solução que implicaria o desvio do curso d'água exclusivamente para seu território. Assim, em setembro de 1991 iniciou as atividades de construção que permitiriam a exploração dessa proposta.

Diante das discussões entre as partes, em maio de 1992 o Governo húngaro remeteu ao Governo eslovaco uma nota verbal colocando fim ao tratado firmado em 1977. Dentre

\footnotetext{
${ }^{10}$ CIJ. Projeto Gabcikovo-Nagymaros (Hungria vs. Eslováquia). Disponível em inglês (tradução nossa) em: <http://www.icj-cij.org/docket/files/92/7375.pdf> acesso em: 16 de fevereiro de 2010.

${ }^{11}$ MACHADO, P. A. L., “O Princípio da Precaução e a Avaliação de Riscos”, Revista dos Tribunais, ano 96, volume 856, fevereiro 2007, p. 41.
} 
as alegações para tal postura, encontravam-se $\mathrm{o}$ estado de necessidade, a impossibilidade de execução e a mudança das circunstancias iniciais.

A situação foi remetida à CIJ (Corte Internacional de Justiça) que, por sua vez, entendeu que apesar de o tratado ter sido firmado em 1977, e as partes terem invocado a Convenção de Viena de 1969, que só entrou em vigor em 1980, os artigos referentes à suspensão e extinção de tratados (artigos 60 e 62) foram reconhecidos como normas consuetudinárias anteriormente.

A Hungria alegou que, ao continuar a implementar o projeto, a Eslováquia não teria levado em consideração as questões ecológicas, tampouco realizado um estudo sobre o impacto ambiental. Alegou ainda que danos materiais e ambientais decorreram da continuidade das obras de construção de diversas eclusas no Rio Danúbio.

Sobre a continuidade das obras, a Corte partiu do princípio de que o meio ambiente é relevante para a vida humana e deve ser uma preocupação dos Estados, principalmente quando suas ações resultarem em prejuízo a ecossistemas estrangeiros. Assim, o órgão julgador se manifestou no parágrafo 140 da sentença de 25 de setembro de 1997:

"Ao longo dos séculos, a humanidade tem, por razões econômicas e outras, constantemente interferido com a natureza. No passado, estas interferências eram muitas vezes feitas sem consideração dos efeitos sobre o ambiente. Devido aos novos parâmetros científicos e de uma crescente conscientização dos riscos para a humanidade para as gerações presentes e futuras da persecução de tais intervenções sem limites, novas normas e padrões têm sido desenvolvidos, estabelecidos em um grande número de instrumentos durante as últimas duas décadas. Essas novas normas têm de ser levadas em consideração, e a tais novas normas dadas bom peso, não só quando os Estados contemplando novas atividades, mas também quando continuar com as atividades iniciadas no passado. Esta necessidade de conciliar o desenvolvimento econômico com a proteção do meio ambiente aptamente está expressa no conceito de desenvolvimento sustentável". ${ }^{12}$

Nesse caso, o desvio unilateral de $80 \%$ a $90 \%$ das águas do Danúbio prejudicou a qualidade das águas e pôs em risco a fauna e a flora da região. Assim, o estado de necessidade teria justificado a interrupção das obras em Nagymaros sem incorrer em

\footnotetext{
${ }^{12}$ CIJ. Projeto Gabcikovo-Nagymaros (Hungria vs. Eslováquia). Disponível em inglês (tradução nossa) em: <http://www.icj-cij.org/docket/files/92/7375.pdf> acesso em: 16 de fevereiro de 2010.
} 
responsabilização por violação do tratado. Estiveram em causa os Princípios do Desenvolvimento Sustentável e da Precaução.

A Corte entendeu que as partes estavam obrigadas a aplicar as normas do Direito Internacional do Meio Ambiente, não apenas visando às atividades futuras, mas também às ações já empreendidas. Fez referência ao conceito de Desenvolvimento Sustentável e propugnou que as partes negociem em boa-fé, harmonizando os objetivos do tratado celebrado com os princípios do Direito Internacional do Meio Ambiente e do Direito dos Cursos de Água Internacionais. Afirmou ainda que a Hungria não teria o direito de suspender e logo abandonar em 1989 os trabalhos relativos ao projeto Nagayamaros e parte do projeto Gabcikovo da qual era responsável de acordo com o tratado de 1977. Por fim, a CIJ requisitou que as partes cooperem para a administração conjunta do projeto e para a instituição de um processo contínuo de monitoramento e proteção ambiental.

Todavia, em crítica a tal decisão, Alexandre Charles KISS (internacionalista contratado pela Hungria) e Jean-Pierre BEURIER afirmam que a Corte "não entendeu que a Hungria tenha trazido a prova de que as águas subterrâneas seriam definitivamente poluídas após alguns decênios. Dessa forma, essa alta jurisdição entendeu não aplicar o princípio da precaução" ${ }^{\text {13. }}$.

Da mesma forma, Christian CAUBET entende que ela não é integralmente correta, pois:

“Em material de proteção do meio ambiente, a sentença revela, para espanto geral dos integrantes da sociedade civil, que a CIJ permanece aquém dos princípios adotados na Conferencia das Nações Unidas sobre o Meio Ambiente e o Desenvolvimento, realizada no Rio de Janeiro em junho de 1992, em particular quanto ao princípio da precaução". ${ }^{14}$

Por outro lado, há que se levar em conta que referida decisão foi exarada somente cinco anos após a Declaração do Rio de Janeiro, de 1992, o que denota um espaço curto de tempo para que a Corte pudesse expor, de maneira aprimorada, as ideias ali consignadas.

\footnotetext{
${ }^{13}$ KISS, A., BEURIER, J., Droit International de l'environnement, Pedone, Paris, $2004^{3}$, p. 136 (tradução nossa).

${ }^{14}$ CAUBET, C. G.., “A Irresistível Ascensão do Comércio Internaiconal: o meio ambiente fora da lei”, Revista Diálogo Jurídico, $\mathrm{n}^{\circ} 15$, jan./fev/mar. 2007, p.13.
} 
Embora este seja um dos principais julgados da CIJ sobre a proteção ambiental, seu conteúdo foi alvo de algumas críticas, principalmente no que tange ao conceito da Corte sobre o Princípio da Precaução. O parágrafo 54 da decisão da CIJ constitui o núcleo de sua concepção sobre perigo e estado de necessidade. Essa questão foi abordada, pois a Hungria baseou-se no estado de necessidade para interromper, em 1989, os trabalhos que deveriam efetuar em razão do tratado celebrado em 1977. "A palavra perigo evoca certamente a ideia de risco, é precisamente nisso que o perigo se distingue do dano materializado, mas não haveria estado de necessidade sem um perigo devidamente dado como certo no momento pertinente, pois somente o temor de um perigo possível não seria suficiente". 15

\section{O CASO DAS 'PAPELERAS' NO MERCOSUL E A PROTEÇÃO AOS DIREITOS HUMANOS}

Outro tema emblemático, principalmente para a América do Sul, diz respeito ao famoso caso das 'papeleras', em que se fez presente o debate sobre a proteção ao meio ambiente e o direito econômico (desenvolvimento sustentável).

A controvérsia, em questão, originada no MERCOSUL, deu-se no ano de $2006^{16}$ e diz respeito à construção de duas fábricas de celulose (as "papeleras") na cidade uruguaia de Gualenguaychú, que faz fronteira com a cidade argentina de Fray Bentos. Referidas cidades são cortadas pelo Rio Uruguai e, no ano de 1975, a Argentina e o Uruguai celebraram o Tratado sobre o Rio Uruguai, visando à proteção do referido rio.

Assim, desde o ano de 2003, a Argentina vinha realizando protestos sobre as pontes que ligam as cidades fronteiriças, acarretando prejuízos ao Uruguai, relativamente à livre circulação de pessoas e de mercadorias.

Em 13 de julho de 2007, a Corte Internacional de Justiça de Haia ${ }^{17}$ negou pedido interposto pela Argentina, em instância de medida cautelar, contra o Uruguai, visando a interromper a construção das referidas fábricas. Entendeu a Corte Internacional de Justiça de Haia que não estariam devidamente comprovados os supostos danos

\footnotetext{
${ }^{15}$ CIJ. Projeto Gabcikovo-Nagymaros (Hungria vs. Eslováquia). Disponível em inglês (tradução nossa) em: <http://www.icj-cij.org/docket/files/92/7375.pdf> acesso em: 16 de fevereiro de 2010.

${ }^{16} \mathrm{http}: / /$ www.mercosur.org.uy/t generic.jsp? contentid $=375 \&$ site $=1 \&$ channel $=$ secretaria $\&$ seccion $=6$ (acesso em 17 de fevereiro de 2010)

${ }^{17} \mathrm{http} / / /$ www.icj-cij.org/docket/files/135/13615.pdf, (acesso em 17 de fevereiro de 2010)
} 
ambientais. Entretanto, reconheceu que incumbiria ao Uruguai se responsabilizar por qualquer dano ambiental e adotar todas as medidas cabíveis visando à proteção ao meio ambiente.

Em data de 20 de abril de 2010, a Corte Internacional de Justiça de Haia ${ }^{18}$ pronunciouse sobre o mérito da referida ação ${ }^{19}$, que teve como fundamento questões de natureza ambiental, ou seja, a não observância do Tratado sobre o Rio Uruguai, celebrado entre ambos os países, em data de 07 de abril de 1961 e que assim estabelece:

“Artigo $7^{\circ}$

As Altas Partes Contratantes acordarlo o estatuto do uso do rio, o qual conterá entre outras matérias as seguintes:

a. Regulamentação comum e uniforme para a segurança da navegação.

b. Regime de pilotagem que respeite as práticas atualmente vigentes.

c. Regulamentação para a manutenção do dragagem e balizamento, em conformidade ao desposto no artigo $6^{\circ}$.

d.Facilidades recíprocas para relevos hidrográficos e outros estudos relacionados ao rio.

e. Disposições para a conservação dos recursos vivos.

f. Disposições para evitar a contaminação das águas".

O Estatuto do Rio Uruguai, assinado em data de 19 de novembro de 1973 assim estabelece:

\section{"CAPITULO VII}

Aproveitamento das águas

Art. 27. - O direito de cada parte de aproveitar as águas do rio, dentro de sua jurisdição para fins domésticos, sanitários, industriais e agrícolas, exercer-se-á sem prejuízo da aplicação do procedimento previsto nos arts. $7^{\circ}$ a 12 quando o aproveitamento seja de realidade suficiente para afetar o regime do rio ou da qualidade de suas águas.

\footnotetext{
${ }^{18} \mathrm{http} / / /$ www.icjcij.org/docket/files/135/15877.pdf?PHPSESSID=ddf0776756e071419f947430d18bc700 (acesso em 20 de maio de 2010).

${ }^{19}$ Atualizações efetuadas em 20 de maio de 2010.
} 


\section{CAPITULO IX}

Conservação, utilização y aproveitamento de outros recursos naturais

Art. 35. - As partes se obrigam a adotar as medidas necessárias a fim de que o manejo do solo e dos bosques, a utilização das águas subterrâneas e da dos afluentes do rio, não causem uma alteração que prejudique sensivelmente o regime do mesmo ou a qualidade de suas águas.

Art. 36. - As partes coordenarão, por intermédio da Comissão, as medidas adecuadas a fim de evitar a alteração do equilíbrio ecológico e controlar pragas e outros fatores nocivos no rio e suas áreas de influência.

Art. 39. - As partes trocarão regularmente, por intermédio da Comissão, a informação pertinente sobre esforço de pesca e captura por espécie.

\section{CAPITULO X}

Contaminação

Art. 40. - Para os efeitos do presente estatuto entende-se por contaminação a introdução direta ou indireta, pelo homem, no meio aquático, de substâncias ou energia das quais resultem efeitos nocivos.

Art. 41. - Sem prejuízo das funções sinalizadas à Comissão na matéria, as partes obrigam-se a:

a) Proteger e preservar o meio aquático e, em particular, prevenir sua contaminação, ditando as normas e adotando as medidas apropriadas, em conformidade aos convênios internacionais aplicáveis e com adequação, quando pertinente, às pautas e recomendações dos organismos técnicos internacionais;

b) Não diminuir em seus respectivos ordenamentos jurídicos:

1. As exigências técnicas em vigor para prevenir a contaminação das água, e

2. A severidade das sanções estabelecidas para os casos de infração.

c) Informar-se reciprocamente sobre toda norma que prevejam ditar com relação à contaminação das águas, com vistas a estabelecer normas equivalentes em seus respectivos ordenamentos jurídicos.

Art. 42. - Cada parte será responsavel, frente à outra, pelos danos inferidos como consequência da contaminação causada por suas próprias atividades ou pelas que em seu território realizem pessoas físicas ou jurídicas. 


\section{CAPITULO XIII}

Comissão Administradora

Art. 49. - As partes criam uma Comissão Administradora do Rio Uruguai, composta de igual número de delegados para cada uma delas.

Art. 50. - A Comissão gozará de personalidade jurídica para o cumplimento de sua responsabilidade.

As partes determinarão os recursos necessários e todos os elementos e facilidades indispensáveis para seu funcionamento.

Art. 51. - A Comissão terá sede na cidade de Paysandú, República Oriental do Uruguai, mas poderá reunir-se nos territórios de ambas partes.

Art. 52. - A Comissão poderá constituir os órgãos subsidiários que estime necessários.

Funcionará em forma permanente e terá sua correspondente secretaria.

Art. 53. - As partes acordarão, por meio de troca de notas, o estatuto da Comissão. Esta ditará seu regulamento interno.

Art. 54. - A Comissão celebrará oportunamente, com ambas partes, os acordos conducentes a determinar os privilégios e imunidades dos membros e pessoal da mesma, reconhecidos pela prática internacional.

Art. 55. - Para adoção das decisões da Comissão, cada delegação terá seu voto.

Art. 56. - A Comissão desempenhará as seguintes funções:

a) Ditar, entre outras, as normas regulamentares sobre:

1. Segurança da navegação no rio e uso do canal principal;

2. Conservação e preservação dos recursos vivos;

3. Treinamento;

4. Prevenção da contaminação;

5. Limpeza de tubulações e cabos sub-fluviais ou aéreos.

b) Coordenar a realização conjunta de estudos e investigações de caráter científico, especialmente os relativos ao levantamento integral do rio.

c) Estabelecer, quando corresponda, os volumes máximos de pesca por espécies e ajustá-los periodicamente. 
d) Coordenar entre as autoridades competentes das partes a ação em matéria de prevenção e repressão de ilícitos.

e) Coordenar a adoção de planos, manuais, terminologia e sistemas de comunicação comuns em matéria de busca e resgate.

f) Estabelecer o procedimento a seguir e a informação a fornecer nos casos em que as unidades de uma parte, que participem de operações de busca e resgate, ingressem no território da outra ou saiam dele.

g) Determinar as formalidades a cumprir nos casos em que deva ser introduzido transitoriamente, no território da outra parte, material para execução de operações de busca e resgate.

h) Coordenar as ajudas à navegação, balizamento e dragagem.

i) Estabelecer o regime jurídico-administrativo das obras e instalações binacionais que se realizem e exercer a administração das mesmas.

j) Publicar e atualizar a Carta Oficial do Rio, com sua taxa de limites, em coordenação com a Comissão criada pelo protocolo.

k) Transmitir de forma clara, às partes, as comunicações, consultas, informações e notificações que se efetuem em conformidade ao estatuto.

1) Cumprir as outras funções que tenham sido determinadas pelo estatuto e aquelas que as partes convenham outorgar por meio de troca de notas ou outras formas de acordo.

Art. 57. - A Comissão informará periodicamente aos movernos das partes sobre o desenvolvimento de suas atividades.

CAPITULO XIV

Procedimento conciliatório

Art. 58. - Toda controvérsia que se suscitar entre as partes com relação ao rio será considerada pela Comissão, a propósito de qualquer delas.

Art. 59. - Se ao término de cento e vinte dias a Comissão não conseguir chegar a um acordo, notificará ambas partes, as quais procurarão resolver a questão por negociações diretas".

Veja-se que pelo Tratado e Estatuto sobre o Rio Uruguai, caberia a ambos os Estados (Argentina e Uruguai) a gestão comum sobre a proteção, exploração e manutenção dos recursos naturais do Rio Uruguai, tendo sido criada uma Comissão Administradora do 
Rio Uruguai, que teria a finalidade de coordenar os trabalhos e as ações entre os Estados, com a finalidade de buscar o melhor aproveitamento sobre o Rio Uruguai.

O reclamo, apresentado pela Argentina na Corte Internacional de Justiça, teve como fundamento o fato de a República Oriental do Uruguai, ao autorizar a construção das fábricas de celulose, não ter observado os procedimentos estabelecidos no Tratado e no Estatuto do Rio Uruguai e mais do que isso, referidas fábricas causariam sérios danos ao meio ambiente.

A Corte Internacional de Justiça, em sua sentença, conforme adiante será comentado, entendeu que, muito embora a República Oriental do Uruguai tenha desrespeitado o Tratado e o Estatuto sobre o Rio Uruguai, a não estabelecer as tratativas bilaterais e prévias, visando a construção das fábricas de celulose, entendeu que não haveria qualquer razão comprovada que justificasse a paralisação das mesmas ou do funcionamento, porquanto não estaria comprovado o alegado dano ao meio ambiente ${ }^{20}$.

A Corte Internacional de Justiça ao examinar as violações da República Oriental do Uruguai, em relação ao Tratado e Estatuto do Rio Uruguai entendeu que:

4. A obrigação de prevenir poluição e preserver o ambiente aquático (Artigo 41)

$* * *$

194. O Tribunal, além do mais, teve ocasião de pressionar, no caso do Projeto Gabcikovo-Nagymaros, que "as Partes juntamente deveriam olhar novamente para os efeitos no meio-ambiente na operação da planta energética de Gabč íkovo" (Projeto Gabcíkovo-Nagymaros (Hungria/Eslováquia), Julgamento, I.C.J. Reports 1997, p. 78, par. 140). O Tribunal é cuidadoso nesses relatos em recolher agora o exame do Artigo 41 do Estatuto de 1975.

$* * *$

273. O Tribunal lembra que as leis internacionais costumeiras concebem a restituição como uma forma de reaparação por dano, sendo a restituição o restabelecimento da situação que existia antes da ocorrência da ação ilegal. O Tribunal lembra ainda que, onde a restituição é materialmente impossível envolve uma sobrecarga de toda proporção para o benefício derivado dela, a reparação toma a forma de compensação ou satisfação, ou mesmo ambas (veja Projeto Gabcíkovo-Nagymaros (Hungria/Eslováquia), Julgamento, I.C.J. Reports 1997, p.

\footnotetext{
${ }^{20} \mathrm{http} / / /$ www.icjcij.org/docket/files/135/15877.pdf?PHPSESSID=ddf0776756e071419f947430d18bc700. (acesso em 20 de maio de 2010)
} 
81, par. 152; Consequências Legais da Construção de um Muro no Territótio Palestino Ocupado, Opinião Consultiva, I.C.J. Reports 2004 (I), p. 198, pars. 152153; Aplicação da Convenção na Prevenção e Punição do Crime de Genocídio (Bósnia e Herzegóvina vs. Sérvia e Montenegro), Julgamento, I.C.J. Reports 2007, p. 233, par. 460; veja também os Artigos 34 a 37 dos Artigos da Comissão de Leis Internacionais sobre a Responsabilidade dos Estados por Ações Internacionais Ilegais).

275. Como apontou o Tribunal (veja parágrafos 154 a 157 acima), as obrigações de conduta sob o Estatuto de 1975 não obriga qualquer proibição subsequente à construção da fábrica de Orion (Botnia) pelo Uruguai, faltando consentimento pela Argentina, depois de expirar o período para negociação. O Tribunal observou, entretanto, que a construção daquela fábrica começou antes das negociações chegarem ao término, quebrando as obrigações de conduta estabelecidas no Estatuto de 1975. Ademais, como o Tribunal julgou, na evidência apresentada a ele, que a operação da fábrica de Orion (Botnia) não resultou na quebra de obrigações substantitvas estabelecidas no Estatuto de 1975 (parágrafos 180, 189 e 265 acima). Como o Uruguai não foi barrado a proceder com a construção e operação da fábrica de Orion (Botnia) depois de expirar o período de negociação e como não rompeu com obrigações substanciais sob o Estatuto de 1975, ordenando que o desmantelamento da fábrica não deveria, na visão do Tribunal, constituir um remédio apropriado pela quebra das obrigações de conduta.

276. Como o Uruguai não quebrou obrigações substantivas surgidas sob o Estatuto de 1975, o Tribunal está igualmente impossibilitado, pelas mesmas razões, de acolher a alegação da Argentina a respeito da compensação pelos danos sofridos alegados em vários setores econômicos, especificamente turismo e agricultura.

$* * *$

281. Finalmente, o Tribunal aponta que o Estatuto de 1975 coloca as Partes sob uma responsabilidade de cooperar uma à outra, nos termos aqui fixados, para garantir a realização de seu assunto e propósito. Esta obrigação de cooperação abrange o monitoramento em andamento de uma instalação industrial, como a fábrica de Orion (Botnia). Naquela consideração o Tribunal registra que as Partes têm uma antiga e efetiva tradição de cooperação e coordenação através da CARU. Por agir conjuntamente através da CARU, as Partes estabeleceram uma real comunidade de interesses e direitos no gerenciamento do Rio Uruguai e na 
proteção deste ambiente. Elas também coordenaram suas ações através do mecanismo comum da CARU, em conformidade com as provisos do Estatuto de 1975, e encontraram soluções apropriadas para suas diferenças entre sua estrutura sem sentir a necessidade de lançar mão de assentimento judicial das disputas determinadas no Artigo 60 do Estatuto até o presente caso fosse trazido ante o Tribunal.

Já dentro do MERCOSUL, o reclamo uruguaio teve como fundamento os prejuízos que os bloqueios, realizados na cidade argentina, estavam causando para a sua economia, violando-se o Tratado de Assunção, 1991, que visa a constituir um Mercado Comum. Entende o Uruguai que, no contexto do MERCOSUL, já vigora o sistema de zona de livre comércio, com algumas exceções.

Invoca, ainda, o Protocolo de Montevidéu, referente à livre circulação de serviços, que está em vigor perante ambos os Estados, bem como o Acordo sobre Transporte Internacional Terrestre (AITT), vigente entre os Estados do Cone Sul, além das normas da OMC, como a Cláusula da Nação Mais Favorecida, Liberdade de Trânsito e Acesso aos Mercados.

Aduz, também, que a questão relativa à livre circulação de pessoas, no contexto da integração, é matéria relativa aos direitos humanos, tutelados em inúmeros tratados sobre a matéria, devidamente ratificados por ambos os países.

Imputa à Argentina a culpa em relação aos referidos protestos, vez que teria a obrigação de combatê-los.

O Tribunal, no que tange às questões decorrentes dos direitos humanos, entendeu que a violação dos mesmos poderia caracterizar uma justificativa para impor barreiras não tarifárias, ou uma restrição ao direito da integração. Sustenta que, caso interviesse combate às referidas manifestações, além de violar os direitos humanos, estar-se-ia imiscuindo em competência estrita das Províncias, violando-se os princípios democráticos de um Estado de Direito.

Quanto à responsabilização da Argentina, o Tribunal perquiriu se o Estado teve culpa para a ocorrência dos referidos fatos, isto é, se foi omisso, no sentido de manter o poder de polícia, para garantir a livre circulação de serviços, concluindo que caberia à parte 
reclamada (Argentina) velar pela livre circulação de serviços, sendo, ainda, responsável pelas omissões dos governos das Províncias.

Quanto à aplicação das normas de Direitos Humanos, o Tribunal entendeu que as referidas questões são de direito interno e não possuem qualquer relação com o direito da integração. e que qualquer restrição ao comércio internacional, invocando o direito interno, implicaria a violação ao Tratado de Viena, artigo 27, no qual a parte não pode invocar uma norma de direito interno como justificativa para descumprir o tratado.

Contemporaneamente, nítida é a relação entre o Direito Constitucional e o Direito da Integração do MERCOSUL, eis que ambos convivem de forma harmômica em uma relação quase de simbiose, em que, internamente, as normativas emanadas pelas instituições do bloco acarretam direitos e deveres aos particulares, quando internalizadas, e, no plano na integração, com a observância, por parte dos Estados, de valores voltados à democracia e aos direitos humanos, cada vez mais o MERCOSUL deve se preocupar com as referidas políticas.

Quanto às manifestações, o Tribunal entendeu que, com o passar do tempo, foram perdendo a legitimidade, e as controvérsias devam ser solucionadas de forma pacífica.

Quanto à relevância dos prejuízos, o Tribunal entendeu que a sua função precípua é a de corrigir eventuais medidas que estejam distorcendo o comércio regional, de forma a determinar que o Estado reclamado venha a eliminá-las e, somente em um momento posterior, caso as medidas não sejam adotadas, torna-se possível a adoção de medidas compensatórias ou de efeito equivalente, a exemplo do sistema adotado na OMC e no NAFTA.

O Tribunal justifica o referido posicionamento entendendo que a adoção das referidas medidas pode causar dificuldades no comércio entre os países.

Assim, a decisão do Tribunal foi no sentido de determinar que o Estado argentino adote medidas visando a prevenir eventuais futuros protestos na região, de forma a oferecer garantias adequadas para que tais protestos não venham a ocorrer.

Sem dúvida, trata-se de um precedente importantíssimo, no MERCOSUL, notadamente porque a controvérsia envolveu uma economia menos favorecida, que é o Uruguai, e que está recebendo investimentos na ordem de U\$1,8 bilhões de dólares. 
A controvérsia em tela, mais do que questões relativas ao livre comércio e ao meio ambiente, tratou de pontos sensíveis a qualquer processo de integração, como é o caso do direito à exploração econômica e sustentável do meio ambiente, proteção aos direitos humanos e à democracia.

Trata-se, no MERCOSUL, de valores que, agora, começam a ser debatidos e, cada vez mais, deverão estar presentes nas agendas de nossos negociadores, tornando-se necessária, mais do que nunca, a participação direta do cidadão, pela integração, a fim de que sejam definidos os objetivos que mais interessem.

O laudo arbitral examinado é emblemático dentro do direito da integração do MERCOSUL, porque envolve não somente temas de comércio internacional, mas temas correlatos e de sensível importância ao processo integracionista, como a dicotomia proteção ao meio ambiente e desenvolvimento sustentável.

O que se pode constatar é que a República Oriental do Uruguai é um Estado com uma economia quase que estagnada, e a construção e a instalação das referidas fábricas de celulose em muito contribuiriam para o aumento da economia daquele país.

Há que se destacar, igualmente, existir, entre os países, um tratado anterior que tem por finalidade proteger o Rio Uruguai, sendo vedada a adoção de qualquer medida causadora de poluição àquele rio.

Todavia, a proteção ao meio ambiente não pode, de forma alguma, prejudicar as economias dos países e a integração entre os Estados, decorrendo, daí, a aplicação do conceito de desenvolvimento sustentável, isto é, os Estados possuem a soberania para, dentro de seu território, explorar o meio ambiente, desde que referidas condutas não acarretem prejuízos para terceiros Estados. Na hipótese da constatação de danos ao meio ambiente, a conduta não poderá ser adotada e o Estado deverá ser responsabilizado internacionalmente.

Vale destacar que, no caso em exame, o que prevaleceu foi a questão econômica, notadamente, porque não restou comprovado qualquer dano ou prejuízo ao meio ambiente.

Há que se levar em consideração, também, no caso das "papeleras", a questão relativa à proteção aos direitos humanos, na exata medida de, tanto as políticas voltadas à proteção ao meio ambiente, como as voltadas ao livre comércio, dentro do MERCOSUL, devem ter como destinatário final a própria pessoa humana, motivo pelo 
qual se defende, neste artigo, serem a proteção ao meio ambiente e o desenvolvimento sustentável elementos indissociáveis e que devem ser considerados como direitos humanos.

\section{CONSIDERAÇÕES FINAIS}

Em vista dos argumentos apresentados, bem como dos estudos de Casos em comento, resta evidente a conexão existente entre a proteção dos direitos humanos e o ambiental. Os dois sistemas contribuíram para o progressivo enfraquecimento do "domínio reservado" dos Estados, uma vez que tanto o tratamento conferido aos cidadãos, como a proteção ambiental tornaram-se matéria de legítima preocupação internacional.

A proteção globalizada pretende, em última análise, a produção de um Direito Ambiental mundial, não significando desprezar as estruturas estatais e as instituições locais. Mais do que isso, trata-se de encontrar uma conscientização de toda a humanidade, no sentido de que o meio ambiente seja protegido e tutelado, sem que implique, necessariamente a perda do direito de soberania dos Estados em explorá-lo.

Cumpre observar que o Desenvolvimento Sustentável vem direcionando os países em direção à perspectivas que integrem a preocupação ambiental, nos discursos e nas práticas governamentais, a bem dos indivíduos e do planeta. Com essa nova ordem jurídica, os Estados mostraram-se inclinados a mudar sua postura em relação à forma de lidar com a política, com a economia, com a matriz energética, com a cultura, com a coexistência individual e coletiva, com a saúde, com a vida e com a efetivação dos Direitos Humanos. Os Tratados, Princípios e Costumes pertinentes ao tema inseriram valores globais que limitam a ação dos homens e dos Estados, estabelecendo comportamentos, padrões e limites para a utilização dos recursos ambientais.

De todo o exposto, observa-se que, atualmente, devem ser ponderados três elementos: a autodeterminação, que rege a soberania permanente sobre recursos e riquezas naturais de um Estado; o direito ao desenvolvimento, inerente a qualquer país; a proteção do meio ambiente ecologicamente equilibrado. A autodeterminação, a soberania e o desenvolvimento não podem ser considerados argumentos válidos para o uso descontrolado dos recursos ambientais, devido ao risco de ocorrerem danos de abrangência transfronteiriça e transgeracionais. 


\section{REFERÊNCIAS BIBLIOGRÁFICAS}

CAUBET, C. G., “A Irresistível Ascensão do Comércio Internaiconal: o meio ambiente fora da lei”, Revista Diálogo Jurídico, n¹5, jan/fev/mar 2007.

CIJ. Projeto Gabcikovo-Nagymaros (Hungria vs. Eslováquia). Disponível em inglês em: $<$ http://www.icj-cij.org/docket/files/92/7375.pdf $>$ acesso em: 16 de fevereiro de 2010.

CIJ. Pulp Mills on the River Uruguay. Disponível em inglês em: $<$ http://www.icjcij.org/docket/files/135/13615.pdf > acesso em: 17 de fevereiro de 2010.

DERANI, C., Direito Ambiental Econômico, Max Limonad, São Paulo,1997.

GUERRA, S. C. S., Direito Internacional Ambiental. Maria Augusta Delgado, Rio de Janeiro, 2006.

KISS, A., BEURIER, J., Droit International de l'environnement, Pedone, Paris, $2004^{3}$.

MACHADO, P. A. L., “O Princípio da Precaução e a Avaliação de Riscos”. Revista dos Tribunais, ano 96, volume 856, fevereiro 2007.

MERCOSUR. Laudo Arbitral. Disponível em espanhol: $<$ http://www.mercosur.org.uy/t_generic.jsp?contentid=375\&site=1\&channel=secretaria $\&$ seccion $=6>($ acesso em 17 de fevereiro de 2010)

MILARÉ, E., Direito do Ambiente: doutrina, prática, jurisprudência, glossário., Ed. Revista dos Tribunais, São Paulo, 2001. 